\title{
MOVIMENTOS DE MASSA NA REGIÃO DE CARAGUATATUBA E SÃO SEBASTIÃO (SP) ENTRE 1967 A 2011: UTILIZAÇÃO DE CICATRIZES DE ESCORREGAMENTO COMO SUBSÍDIO A ESTUDOS DE RETRO- ANÁLISE
}

\author{
Claudia Vanessa dos Santos Corrêa ${ }^{(a)}$, Fábio Augusto Gomes Vieira Reis ${ }^{(b)}$, Lucília Carmo \\ Giordano $^{(\mathrm{c})}$, Camila Jardinetti Chaves ${ }^{(\mathrm{d})}$, Beatriz Marquez Gabelini ${ }^{(\mathrm{e})}$, Rodrigo Cerri ${ }^{(\mathrm{f})}$ \\ (a) Instituto de Geociências e Ciências Exatas, Universidade Estadual Paulista "Júlio de Mesquita Filho", \\ claudiageobrax@yahoo.com.br \\ (b) Instituto de Geociências e Ciências Exatas, Universidade Estadual Paulista "Júlio de Mesquita Filho", \\ fabioreis@rc.unesp.br \\ (c) Instituto de Geociências e Ciências Exatas, Universidade Estadual Paulista "Júlio de Mesquita Filho", \\ lcg@ecogeologia.com.br \\ (d) Instituto de Geociências e Ciências Exatas, Universidade Estadual Paulista "Júlio de Mesquita Filho", \\ camila.j.chaves@gmail.com \\ (e) Instituto de Geociências e Ciências Exatas, Universidade Estadual Paulista "Júlio de Mesquita Filho", \\ bgabelini@gmail.com \\ ${ }^{(f)}$ Instituto de Geociências e Ciências Exatas, Universidade Estadual Paulista "Júlio de Mesquita Filho", \\ roocerri@gmail.com
}

\section{Eixo: GEOGRAFIA FÍSICA E DESASTRES NATURAIS}

\begin{abstract}
Resumo
O objetivo deste trabalho é de discutir os resultados obtidos pela análise temporal da ocorrência de movimentos de massa em Caraguatatuba e São Sebastião (SP), entre 1967 e 2011, através da fotointerpretação de cicatrizes de escorregamento e levantamento bibliográfico. Para tal, foram utilizadas cartas topográficas em escala 1:50.000 do IBGE das folhas Caraguatatuba, Pico do Papagaio, Maresias e São Sebastião, mapa geológico em escala 1:50.000 das folhas Caraguatatuba e Pico do Papagaio e São Sebastião, ortofotos em escala 1:10.000 da Emplasa (2011) e mapa de cicatrizes de escorregamento (FÚLFARO et al., 1976). Em ambos os cenários os locais mais atingidos por movimentos de massa foram aqueles situados na região serrana, devido às suas características fisiográficas (altos valores de declividade, relevo escarpado a serrano e existência de canais de primeira ordem). Estes resultados serão utilizados para subsidiar estudos de retro-análise e como inputs para modelagens numéricas com softwares de simulação 3D.
\end{abstract}

Palavras chave: Movimentos de massa, Cicatrizes de escorregamento, Retro-análise, Ortofotos

\section{Introdução}

Movimentos de massa são processos dinâmicos que ocorrem, em geral, em vertentes. Esses eventos podem ser desencadeados pela interação entre diferentes fatores endógenos, tais como tipo de solo, de rocha ou de forma do terreno, e fatores exógenos, como variáveis climáticas, fatores antrópicos, entre outros (BISPO et al., 2011). Os movimentos provenientes dessas interações correspondem ao 
desprendimento e transporte de solo e/ou material rochoso vertente abaixo, devido a sua instabilidade condicionada pela gravidade, podendo ser intensificada pela ação de outros agentes, tais como a água ou vento (CHORLEY et al., 1984; FERNANDES; AMARAL, 1996; SESTINI, 1999).

De acordo com a ONU (1993), esses fenômenos são os que causam maiores prejuízos financeiros e mortes no mundo. Entretanto, são processos importantes no modelamento do relevo e têm sua ocorrência ligada às encostas. Nas cidades estes assumem, em geral, proporções catastróficas, uma vez que são feitas diversas modificações na paisagem natural que acabam se relacionando com os fatores naturais propiciando a deflagração destes processos (BRUNSDEN; PRIOR, 1984; SILVA-FILHO, 1992; MONTGOMERY, 1994; FERNANDES; AMARAL, 1996; LARSEN; TORRES-SÁNCHEZ, 1998; ZERKAL; ZERKAL, 2004).

Nesse sentido, com o aumento populacional das últimas décadas, em sua maioria sem planejamento adequado, a ocorrência de processos de dinâmica superficial vem aumentando significativamente. A ocupação de encostas íngremes e de margens de córregos sem obedecer a critérios técnicos é um fator que acelera as corridas de massa, e consequentemente, pode aumentar os danos provocados (WRIGHT; KRONE, 1990).

No mundo, existem registros de enormes movimentações de massa com diferentes características, como volume, velocidade, vazão, etc, deflagradas por fatores tanto externos quanto internos (GRAMANI, 2001). O fenômeno ocorre de maneira natural nas regiões serranas e, em cerca de 50 países, são muito frequentemente observados (MIDRIAK, 1985; TAKAHASHI, 1994). Em áreas tropicais e costeiras são comuns os movimentos de massa, que causam enorme destruição na sua trajetória, envolvendo diversos tipos de solos e ambientes geológicos (COLLINS; ZNIDARCIC, 1997).

Segundo dados do Centro de Pesquisa de Epidemiologia em Desastres (CRED) da Organização Mundial da Saúde (OMS), o Brasil está entre os dez países mais afetados por desastres no mundo (EM-DAT, 2008). Neste contexto, Augusto Filho (1992) e Gramani (op.cit.) elaboraram o levantamento dos acidentes mais importantes envolvendo movimentos de massa no Brasil. As áreas mais susceptíveis a ocorrência desses processos no Brasil são as áreas situadas no sopé da Serra do Mar, da Serra da Mantiqueira e da Serra Geral, estendendo-se desde a região Sul até a região Norte. No município de Caraguatatuba, na região da Serra do Mar, em 1967 ocorreu um dos mais expressivos movimentos de massa registrados no estado e no Brasil, ocasionado por fortes chuvas que caíram sobre a região. Estima-se que mais de 30 mil árvores desceram as encostas da Serra do Mar e 
atingiram as porções baixas do relevo. Cerca de 400 moradias foram total ou parcialmente destruídas e, oficialmente, foram contabilizados 120 mortos e milhares de pessoas desabrigadas (GOMES et al., 2008). Gramani (2001) afirma que devido à elevada declividade de suas encostas (com ângulos maiores que $35^{\circ}$ ) e suas chuvas intensas e concentradas, os movimentos de massa - principalmente corridas de detritos e escorregamentos translacionais - são frequentemente observados nestes locais.

Para auxiliar na compreensão e entendimento destes processos, destacam os estudos de retro-análise, que se pautam no resgate histórico das variáveis que influenciaram a sua ocorrência como tentativa de mitigá-los e preveni-los. A combinação de estudos de retro-análise à interpretação de imagens de sensoriamento remoto, da caracterização geológico-geotécnica e da análise do uso e da ocupação da terra fornecem dados que permitem um maior entendimento dos processos que estão envolvidos em tais eventos (CORRÊA et al., 2015).

Assim, este trabalho objetiva apresentar e discutir os resultados obtidos pela análise temporal da ocorrência de movimentos de massa em Caraguatatuba e São Sebastião (SP), entre os anos de 1967 e 2011, através da fotointerpretação de cicatrizes de escorregamento e levantamento bibliográfico, cuja finalidade é indicar quais são os locais com maior susceptibilidade à ocorrência destes processos. Ademais, os resultados obtidos serão utilizados futuramente como subsídio a estudos de retro-análise.

\section{Caracterização da área de estudo}

A área de estudo compreende às bacias hidrográficas do Rio Santo Antônio, do Rio Juqueriquerê e do Rio São Francisco, localizadas nos municípios de Caraguatatuba e São Sebastião (SP), no contexto geomorfológico do Planalto Atlântico e da Província Costeira (Figura 1). A Província Costeira é dividida por Almeida (1964) em Serranias Costeiras e Zona da Baixada Litorânea. As planícies possuem ocorrência restrita distribuídas por um litoral bastante recortado, onde são frequentes as enseadas e praias. A costa é abruptamente interceptada pela borda oriental do Planalto Atlântico com ocorrência de pontões rochosos perpendiculares à direção geral desta estrutura, os quais favorecem a formação de baías.

Segundo o mesmo autor, a ação dos movimentos neotectônicos, representada pelos movimentos de blocos de falhas, é responsável pelo desenvolvimento de rifts e soerguimento da Serra do Mar e Mantiqueira. Esses movimentos ocorreram basicamente ao longo de antigas linhas de fraqueza do Pré-cambriano, com direção predominante leste-nordeste determinando a linha de costa atual. Esta área encontra-se totalmente inserida no Embasamento Cristalino em trecho do cinturão de cisalhamento transcorrente Paraíba do Sul. Com relação à litologia da região serrana, destaca-se a ocorrência de rochas polimetamórficas de idade 

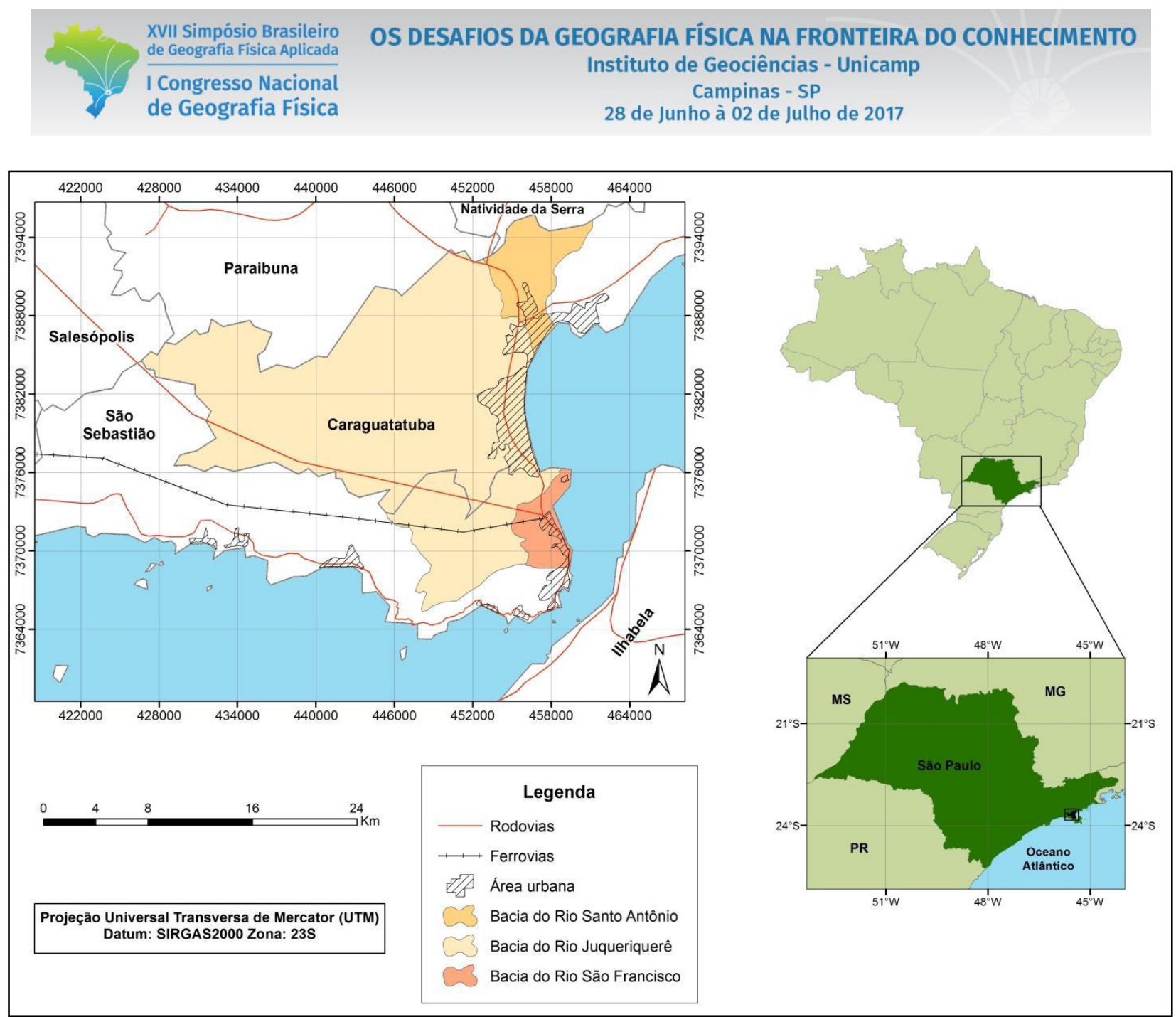

arqueana (migmatitos, gnaisses, granito-gnaisses, biotita gnaisses), granitóides foliados do proterozóico superior, rochas cataclásticas cambro-ordivicianas e intrusões básicas localizadas, de idade mesozóica (geralmente na forma de diques).

Figura 1 - Localização da área de estudo

\section{Materiais e métodos}

Para a elaboração do presente trabalho foram utilizados os seguintes materiais: cartas topográficas em escala 1:50.000 do IBGE das folhas Caraguatatuba (SF-23-Y-D-VI-1), Pico do Papagaio (SF-23-Y-D-V2), Maresias (SF-23-Y-D-V-4) e São Sebastião (SF-23-Y-D-VI-3) (IBGE, 1973; 1974a; 1974b; 1975), mapa geológico em escala 1:50.000 das folhas Caraguatatuba e Pico do Papagaio (CPRM, 1982; 1991) e São Sebastião (IG, 1996), além de ortofotos em escala 1:10.000 da Emplasa (2011) e mapa de cicatrizes de escorregamento elaborado por Fúlfaro et al. (1976). 
No que tange ao método, primeiramente as cartas topográficas, o mapa geológico e as ortofotos da Emplasa (2011) foram georreferenciados em sistema de coordenada plana UTM (Universal Transversal de Mercator), com datum SIRGAS2000, conforme as orientações do IBGE (IBGE, 1997). Toda a base cartográfica foi organizada, georreferenciada e inserida em ambiente de Sistema de Informação Geográfica (ArcGis 10.2.2). Os dados que possuíam datuns diferentes foram submetidos à transformação geodésica baseada no método Molodensky, que transforma diretamente coordenadas geodésicas, dadas em latitude, longitude e altura elipsoidal, por meio do aumento da componente horizontal e vertical, sem necessidade de uma conversão intermediária das coordenadas geodésicas para o sistema geodésico cartesiano (FRAU et.al., 2012).

Posteriormente, foi realizada a etapa de fotointerpretação para extração de cicatrizes de escorregamento nas ortofotos da Emplasa (2011). Seguindo a mesma metodologia de Ferreira et al. (2008), a extração das cicatrizes foi efetuada através de interpretação visual, diretamente na tela do computador, utilizando-se a sobreposição de curvas de nível da base topográfica digital, para favorecer a identificação das feições e esclarecimento de eventuais dúvidas. Os principais critérios utilizados para o reconhecimento das cicatrizes dos escorregamentos foram: ausência de vegetação, tonalidade, cor, posição na vertente, forma, dimensão e orientação na vertente (FERREIRA et al., 2008).

Em seguida, com finalidade de realizar a análise temporal, foram digitalizadas e vetorizadas as cicatrizes de escorregamento levantadas por Fúlfaro et al. (1967), que basearam-se em fotografias aéreas da VASP (1973), em escala 1:25.000, para analisar os movimentos de massa que ocorreram na região de Caraguatatuba (SP), em 1967.

Por fim, foram gerados mapas de declividade e hidrografia da área de estudo, selecionando-se como dados de entrada as curvas de nível vetorizadas das cartas topográficas supracitadas, que foram submetidas a processos de geoprocessamento na mesma plataforma SIG.

\section{Resultados e discussões}

\subsection{Cicatrizes de escorregamento de 1967 (Fúlfaro et al., 1976)}

Fúlfaro et al. (1976) identificaram 483 cicatrizes de escorregamento na região de Caraguatatuba (SP), que segundo os autores, referem-se ao grande evento que ocorreu no local no ano de 1967 (Figura 2). As 


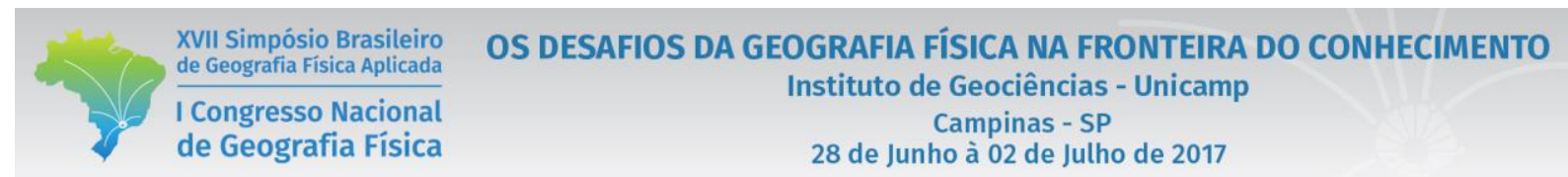

figuras 3, 4 e 5 exibem as informações relativas à declividade, geologia e hidrografia da área de estudo, respectivamente.

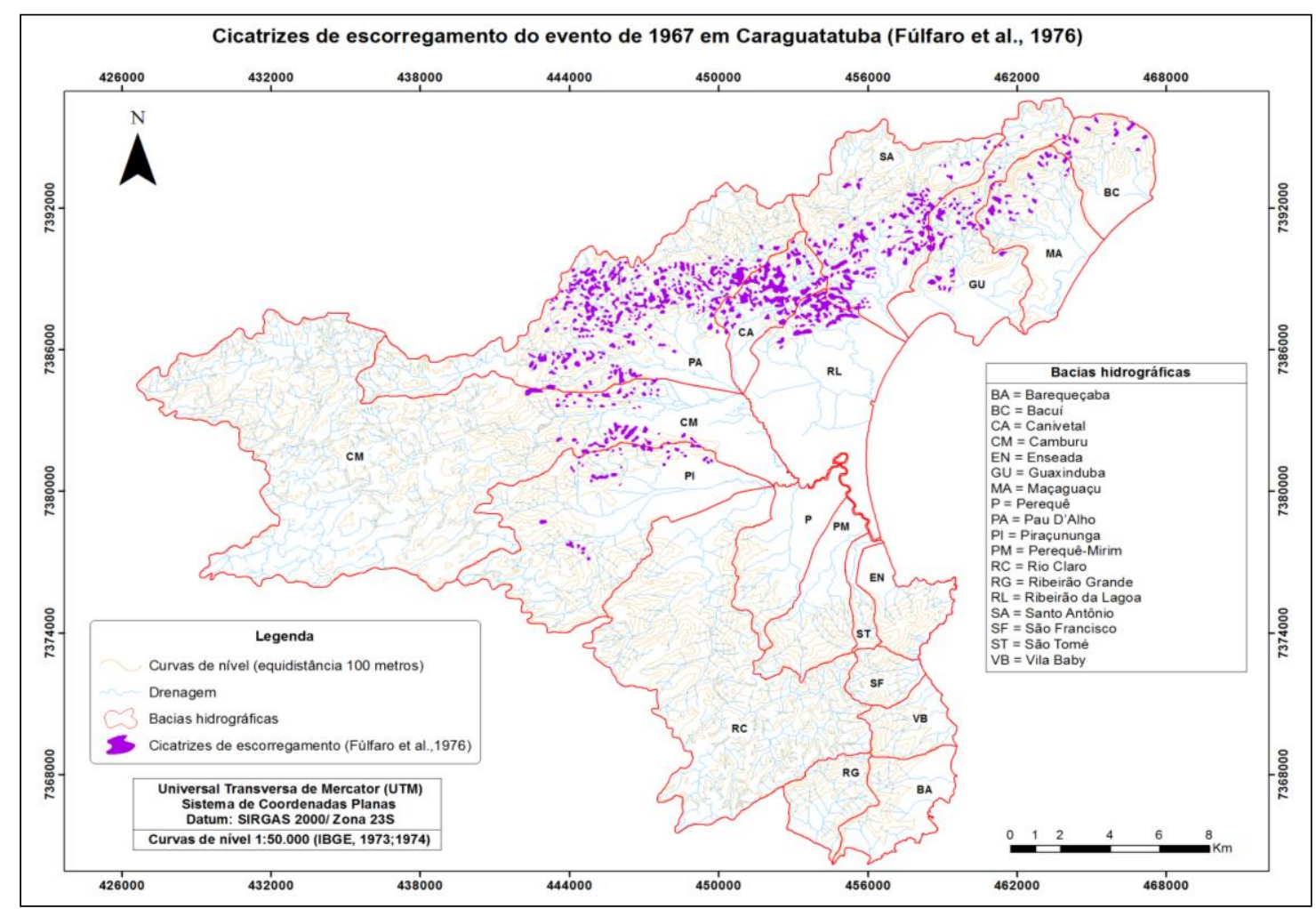

Figura 2 - Espacialização das cicatrizes de escorregamento do evento de 1967 na região de Caraguatatuba (SP).

Fonte: Fúlfaro et al. (1976)

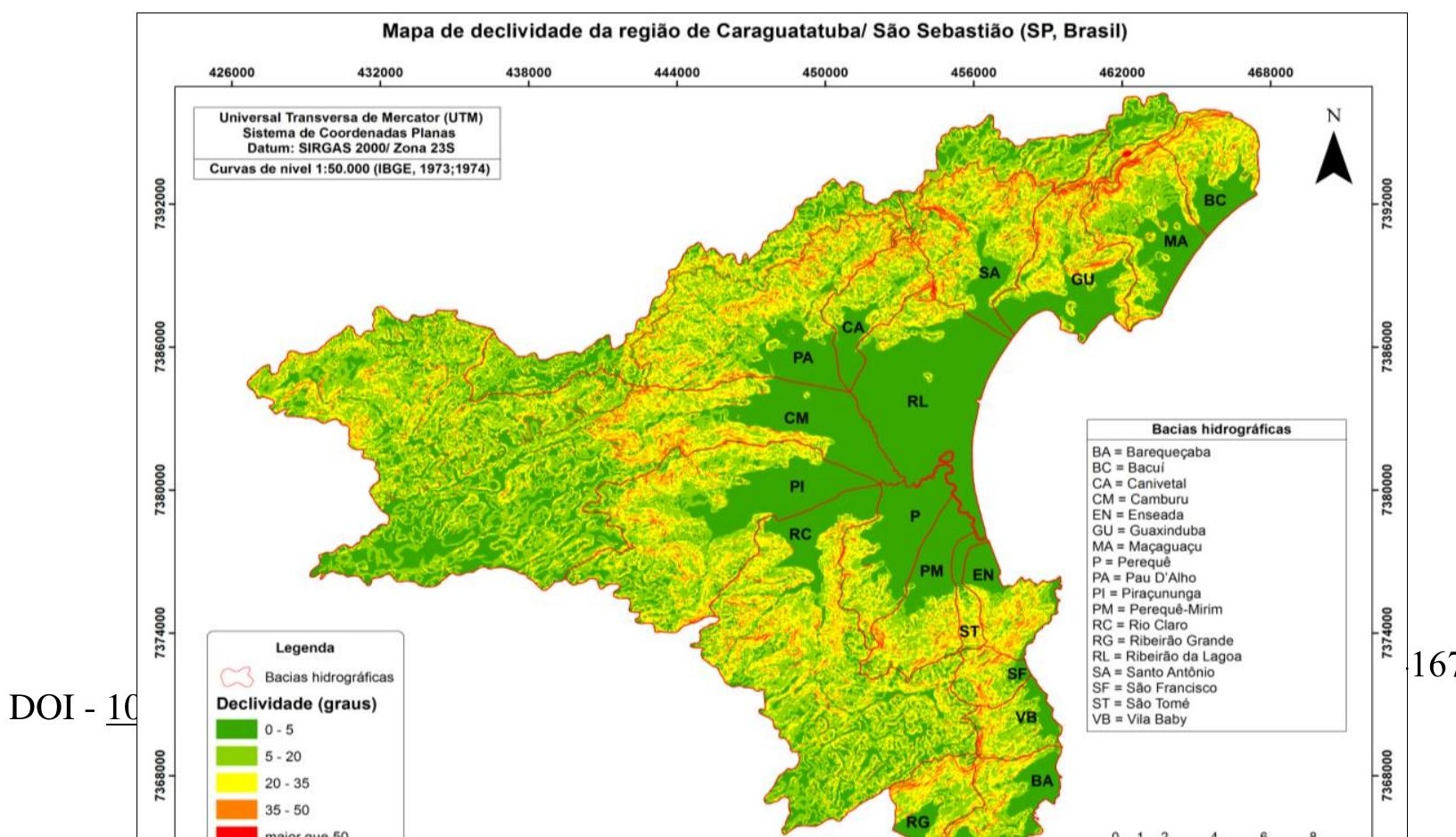


Figura 3 - Mapa de declividade da região de Caraguatatuba e São Sebastião (SP).

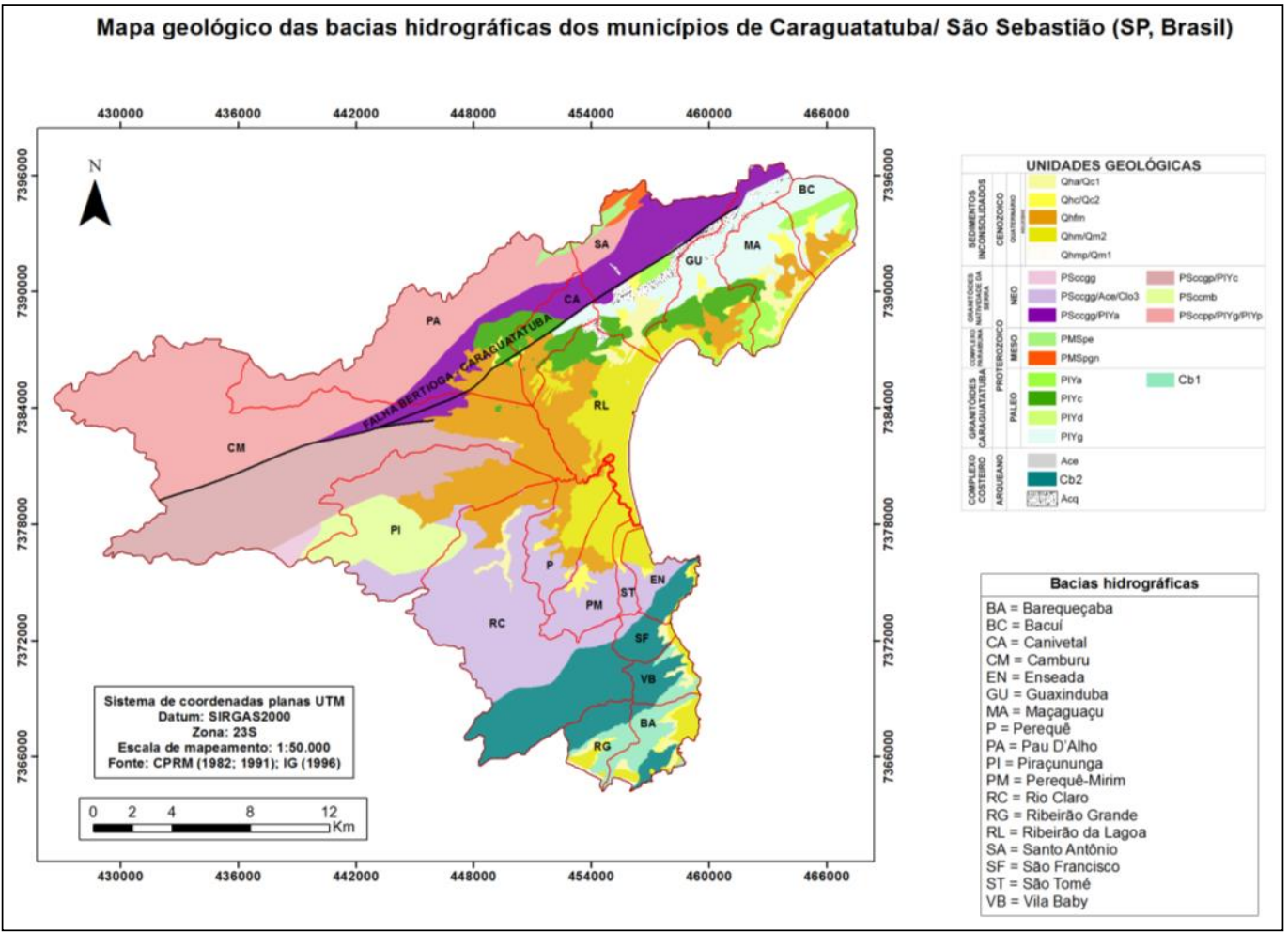

Figura 4 - Mapa geológico da região de Caraguatatuba e São Sebastião (SP).

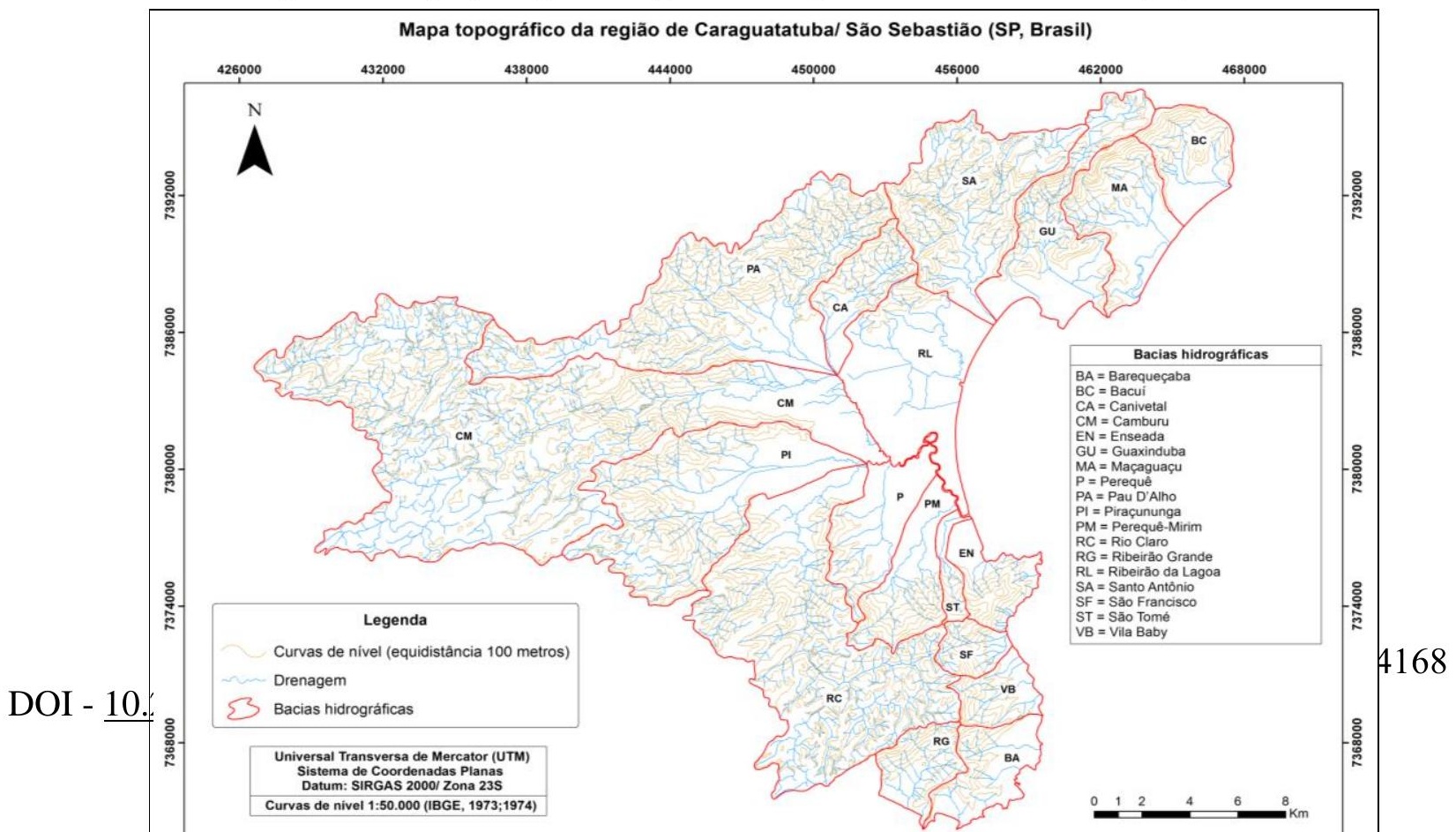


Figura 5 - Mapa hidrográfico com as curvas de nível da região de Caraguatatuba e São Sebastião (SP).

A maior parte das cicatrizes concentram-se nas bacias hidrográficas do Pau D’Alho, Canivetal e Santo Antônio. Essas bacias estão situadas principalmente em unidades geológicas do Embasamento Cristalino, com valores de declividade maiores que $20^{\circ}$. Ademais, por estas bacias percorre a falha geológica Bertioga-Caraguatatuba, o que caracteriza estes locais como mais susceptíveis a qualquer instabilidade no terreno.

É possível observar que os canais de primeira ordem principalmente foram atingidos pelos escorregamentos generalizados, que, segundo a literatura, rapidamente se modificaram para extensas corridas de detritos (GRAMANI, 2011). Nesse sentido, nos trabalhos de campos realizados no local verificou-se a existência de resquícios deste grande processo, o que corrobora a ocorrência de movimentos de massa do tipo debris flow pretéritos.

\subsection{Cicatrizes de escorregamento de 1967 a 2011}

Foram registradas 406 cicatrizes de escorregamento na área em questão entre os anos de 1967 a 2011, identificadas nas ortofotos da Emplasa (2011), conforme indica a Figura 6.

Em relação aos movimentos de massa ocorridos entre 1967 e 2011, cabe destacar que optou-se por diferenciar as cicatrizes de escorregamento que de fato foram deflagradas entre o período supracitado daquelas que não foram recuperadas até o ano de 2011. Desta forma, é possível afirmar com maior clareza quais locais foram atingidos por movimentos de massa após o ano de 1967.

Nesse sentido, é possível notar que outras bacias hidrográficas, localizadas ao sul da área de estudo, apresentaram registros de movimentos de massa após o ano de 1967. Entretanto, as características fisiográficas dos locais atingidos se assemelham àquelas do evento de 1967: unidades geológicas relacionadas ao Embasamento Cristalino, declividades com valores maiores que 200 e morfologias escarpadas e serranas. Ademais, nota-se que algumas cicatrizes de escorregamento do evento de 1967, que não foram recuperadas até o ano de 2011, atuaram como locais de maior vulnerabilidade a movimentos de massa, uma vez que existem resquícios destes processos adjacentes ou muito próximos a estas cicatrizes. 


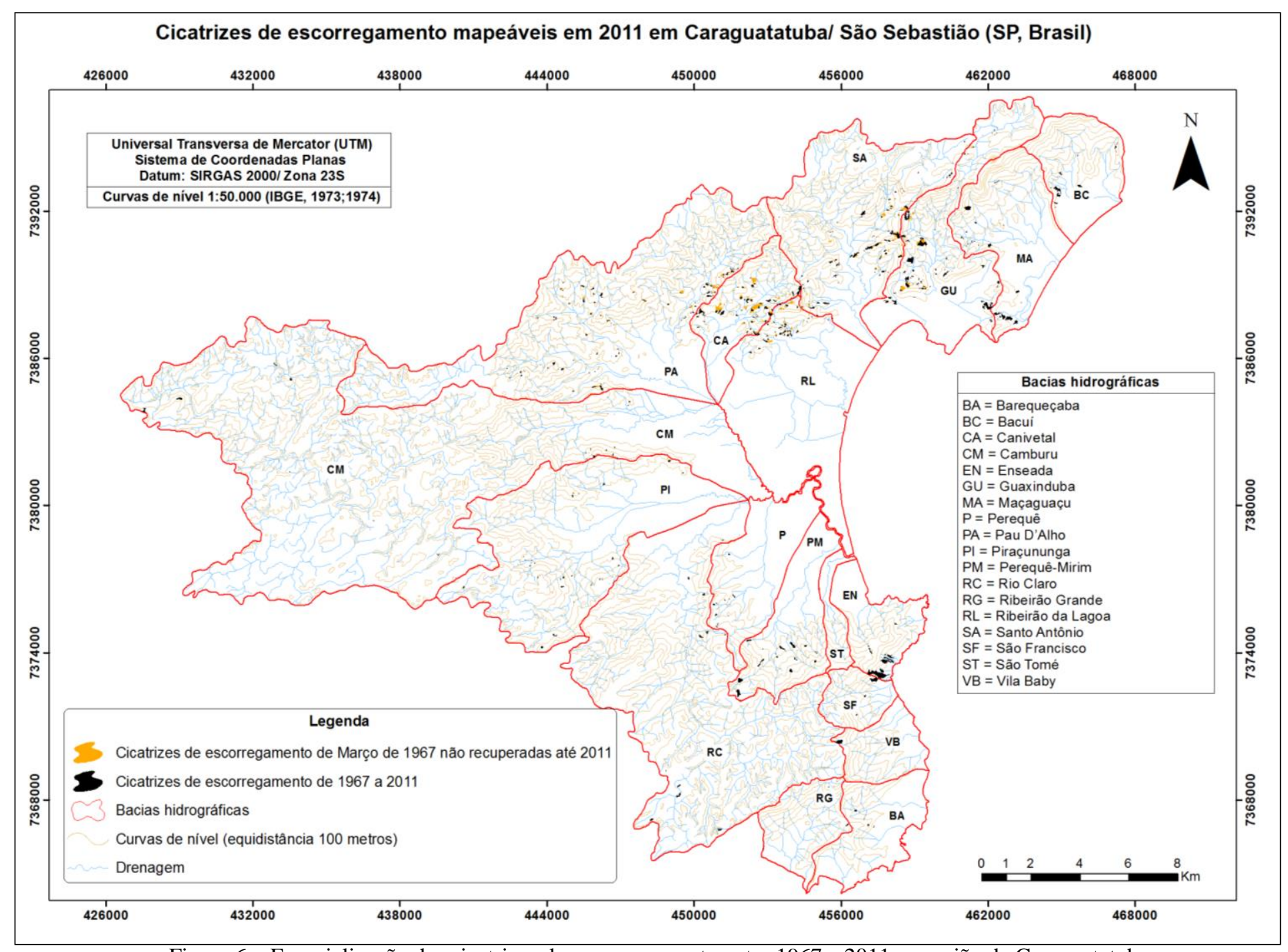

Figura 6 - Espacialização das cicatrizes de escorregamento entre 1967 a 2011 na região de Caraguatatuba e

São Sebastião (SP).

\section{Considerações finais}


Observou-se que as bacias hidrográficas localizadas na região serrana possuem maior potencialidade à ocorrência de processos de movimentos de massa devido às suas características fisiográficas (altos valores de declividade, relevo escarpado a serrano e existência de canais de primeira ordem).

Ademais, as bacias hidrográficas do Rio Santo Antônio e do Córrego do Canivetal possuem maior potencialidade de geração desses processos, devido às suas características geológico-geotécnicas, tais como altas declividades e localização no Embasamento Cristalino.

As cicatrizes de escorregamento de 1967 se configuraram como locais de maior vulnerabilidade a ocorrência de eventos posteriores, uma vez que foram identificados resquícios destes eventos adjacentes ou muito próximos às mesmas.

Deve-se também considerar, para futuros posteriores, a dinâmica pluviométrica do local, uma vez que a ocorrência de grandes eventos chuvosos também está relacionada à deflagração de movimentos de massa.

Futuramente, com a finalidade de determinar o raio de alcance de possíveis movimentos de massa no local, serão empregadas modelagens numéricas na área a partir de softwares de simulação 3D.

\section{Agradecimentos}

Os autores agradecem a Agência Nacional de Petróleo (ANP) pelo fomento à pesquisa e à bolsa de pesquisa concedida. O trabalho foi desenvolvido no âmbito do Programa de Formação de Recursos Humanos em Geologia e Ciências Ambientais aplicadas ao Petróleo da UNESP - PRH 05, com apoio do $\mathrm{PRH} / \mathrm{ANP}$.

\section{Bibliografia}

ALMEIDA, F. F. M. Fundamentos Geológicos do Relevo Paulista. Boletim do Instituto de Geografia e Geologia, São Paulo, n. 41, p. 169-263. 1964.

AUGUSTO FILHO, O. Cartas de risco de escorregamentos: uma proposta metodológica e sua aplicação no município de Ilhabela, SP. Dissertação (Mestrado em Engenharia), Escola Politécnica, Universidade de São Paulo, São Paulo, 1992. 162 p.

BISPO, P.C.; ALMEIDA C.M.; VALERIANO, M.; MEDEIROS, J.S.; CREPANI, E. Análise da susceptibilidade aos movimentos de massa em São Sebastião (SP) com uso de métodos de inferência espacial. São Paulo: UNESP/ Geociências, 2011. 100 p.

BRUNSDEN, D.; PRIOR, D.B. Slope Instability. Chichester: John Wiley, 1984.

CHORLEY, R.J.; SCHUMM, S.A.Y.; SUGDEN, D.E. Geomorphology. Londres: Methuen, 605 p., 1984.

COLLINS, B.; ZNIDARCIC, D. Triggering Mechanisms of Rainfall Induced Debris Flows. In: 2nd Panam. Symp. Landslides, 2o COBRAE. Rio de Janeiro, 1997. p. 277-286. 
CORREAA, C.V.S.; REIS, F.A.G.V.; AMARAL, A.M.C.; COURA, M.M.; GIORDANO, L.C.; CHAVES, C.J. Caracterização geológica-geomorfológica dos principais movimentos de massa na região sudeste do Brasil entre os anos de 1967 e 2011 como subsídio a estudos de retroanálise. In: Congresso Brasileiro de Geologia de Engenharia e Ambiental, 15, Recife, 2015. Anais... Bento Gonçalves: ABGE, 2015. CD-ROM.

CPRM - COMPANHIA DE PESQUISA DE RECURSOS MINERAIS. Mapa geológico da Folha Caraguatatuba. SF-23-Y-D-VI-1. São Paulo: CPRM, 1982. Escala 1:50.000.

CPRM - COMPANHIA DE PESQUISA DE RECURSOS MINERAIS. Mapa geológico da Folha Pico do Papagaio. SF-23-Y-D-V-2. São Paulo: CPRM, 1991. Escala 1:50.000.

EM-DAT. International Disaster Database. 2008. Disponível em: 〈www.emdat.be>. Acesso em: 02 fev. 2017.

FERNANDES, N.F.; AMARAL, C.P. Movimentos de massa: uma abordagem geológico-geomorfológica. In: Guerra, A.J.T.; Cunha, S.B. (Orgs.). Geomorfologia e Meio Ambiente. Rio de Janeiro: Bertrand, 1996. p. $123-194$.

FERREIRA, M. V.; RIEDEL, P. S; LOPES, E.S.S.; MERINO, E.R. Comparação entre diferentes critérios para elaboração de mapas de suscetibilidade aos escorregamentos- exemplo do município de Cubatão, SP. Revista Brasileira de Cartografia, v. 60, p. 385-400, 2008.

FRAU, C. M.; PINO, L. M.; ROJAS, Y. O.; HERNÁNDEZ, Y. M. Modelamiento geométrico del cambio de coordenadas UTM causadas por mudanza de referencial geodésico. Caso SIRGAS - Chile. Boletim Ciências Geodésicas, Curitiba, v. 18, n. 4, p.583-604, 2012.

FULFARO, V.; PONÇANO, W. L.; BISTRICHI, C. A.; STEIN, D. P. Escorregamentos de Caraguatatuba: expressão atual, e registro na coluna sedimentar da planície costeira adjacente. In: Congresso Brasileiro de Geologia de Engenharia, 1976. Anais... Rio de Janeiro: ABGE, 1976. v. 2, p. 341-350.

GOMES, C.L.R.; OGURA, A.T.; GRAMANI, M.F.; CORSI, A.C.; ALAMEDDINE, N. Retro-análise da corrida de massa ocorrida no ano de 1967 nas encostas da Serra do Mar, vale dos rios Camburu, Pau D ${ }^{\text {ee }}$ Alho e Canivetal, município de Caraguatatuba - SP: quantificação volumétrica dos sedimentos depositados nas planícies de inundação. In: Congresso Brasileiro de Geologia de Engenharia e Ambiental, 12, Recife, 2008. Anais... Recife: ABGE, 2008. CD-ROM.

GRAMANI, M.F. Caracterização geológica-geotécnica das corridas de detritos ("Debris Flows") no Brasil e comparação com alguns casos internacionais. Dissertação (Mestrado em Engenharia de Solos), EPUSP - Escola Politécnica, Universidade de São Paulo, São Paulo. 2001. 372 p.

IBGE - INSTITUTO BRASILEIRO DE GEOGRAFIA E ESTATÍSTICA. Folha de Maresias. São Paulo: IBGE, 1973. SF-23-Y-D-V-4. Escala 1:50.000.

IBGE - INSTITUTO BRASILEIRO DE GEOGRAFIA E ESTATÍSTICA. Folha de Caraguatatuba. São Paulo: IBGE, 1974a. SF-23-Y-D-VI-1. Escala 1:50.000.

IBGE - INSTITUTO BRASILEIRO DE GEOGRAFIA E ESTATÍSTICA. Folha do Pico do Papagaio. São Paulo: IBGE, 1974b. SF-23-Y-D-V-2. Escala 1:50.000.

IBGE - INSTITUTO BRASILEIRO DE GEOGRAFIA E ESTATÍSTICA. Folha de São Sebastião. São Paulo: IBGE, 1975. SF-23-Y-D-VI-3. Escala 1:50.000.

IBGE - INSTITUTO BRASILEIRO DE GEOGRAFIA E ESTATÍSTICA. Sistema de referência geocêntrico para a América do Sul. Relatório Final Grupos de trabalho I e II. Rio de Janeiro: CDD IBGE, 1997. 122 p. Disponível em: <http://www.ibge.gov.br/>. Acesso em: 25 mar. 2017.

IG - INSTITUTO GEOLÓGICO DO ESTADO DE SÃO PAULO. Mapa geológico do município de São Sebastião. São Paulo: IG, 1996. Escala 1:50.000.

LARSEN, M.C.; TORRES-SANCHEZ, A.J. The frequency and distribution of recent landslides in three montane tropical regions of Puerto Rico. Geomorphology, v. 24, p. 309- 331. 1998.

MIDRIAK, R. Debris Flow and their occurrence in the Czechoslovak High-Mountain West Carpathians. In: International Symposium on Erosion, Debris Flow and Disaster Prevention. Sept., Tsukuba-Japan. p.175-180. 1985. 
MONTGOMERY, D.R. Road surface drainage, channel initiation, and slope instability. Water Resources Research, v. 30, p. 1925-1932. 1994.

ONU - ORGANIZAÇÃO DAS NAÇÕES UNIDAS. Working party on world landslide inventory. Bulletin of the IAEG, 41, p. 5-12. 1993.

SILVA-FILHO, E.P. Movimentos de massa na vertente sul florestada do maciço da Tijuca: casos de fevereiro/1988 nas estradas Dona Castorina e Vista Chinesa. Dissertação (Mestrado em Geografia), Universidade Federal do Rio de Janeiro, 1992.

TAKAHASHI, T. Japan-China Joint Research on the Prevention from Debris Flow Hazards. Intern. Scientific Research Program, nº 03044085. March/1994-Kyoto University, p. 100-113. 1994.

WRIGHT, V.G.; KRONE, R.B. Erosion processes in upland areas. In: FRENCH, R.H. (ed.). Hydraulics/Hidrology of Arid Lands (H2AL). p.142-147. 1990.

ZERKAL, S.V.; ZERKAL, O.V. Simulation flow landslides by particle method. In: International Symposium on landslides, 9, 2004. Rio de Janeiro. Anais... Rio de Janeiro: 2004. 